\title{
Early Botulinum Toxin Treatment of Acute Sixth Nerve Palsy
}

\author{
A. D. N. MURRAY \\ Cape Town, South Africa
}

\begin{abstract}
Summary
Eight patients with total sixth nerve palsy were treated with botulinum toxin injection to the antagonist non-paretic medical rectus, within eight weeks of the onset of the palsy. Within a few days seven of the eight gained fusion without the necessity of a marked head turn, and none complained of confusing reversal of diplopia. The same seven recovered full function. The mean follow-up period after the last injection was 20 months.

Seven palsies were the result of head trauma and one was due to cerebro-vascular disease.

This preliminary report suggests that early botulinum toxin injection of patients with recent onset sixth nerve palsy is beneficial. Although all of the patients may possibly have recovered full lateral rectus function without treatment, the aetiologies of their palsies were of the type that frequently do no resolve. A randomised doubleblind study is necessary more precisely to determine the effectiveness of this form of therapy.
\end{abstract}

The sudden onset of a sixth nerve palsy usually results in debilitating horizontal diplopia. To determine whether symptomatic diplopia in primary gaze can be diminished early on, a group of patients with total sixth nerve palsy were injected with botulinum toxin. The effects upon the deviation and extent of abduction, as well as the patients' subjective response to medial rectus paralysis were assessed.

\section{Patients and Methods}

Eight patients (all males) with total sixth nerve palsy were treated with botulinum toxin injection to the antagonistic non-paretic medial rectus, within eight weeks of the onset of the palsy. The investigational nature of this form of treatment was explained and informed consent was obtained. No patient showed any sign of sixth nerve recovery prior to injection. Seven palsies were the result of head trauma, while one was due to cerebrovascular disease. The average age of patients treated was 37 years (range 8-64 years). Patients were followed for a mean of 33 months after the last injection (range 12-48 months).

Lateral rectus function was assessed as poor $(P)$, fair $(F)$, or good $(G)$ according to clinical force generation testing. Ocular deviations were measured in primary gaze by prism and alternating cover test. Ocular ductions were graded from -5 (maximal limitation) to 0 (full rotation into field of action). Contracture of the medial rectus was determined by passive force duction testing, and was graded from 0 (no contracture) to $3+$ (maximal contracture).

From: Department of Ophthalmology, University of Cape Town and Groote Schuur Hospital.

Correspondence to: A. D. N. Murray, Department of Ophthalmology, University of Cape Town Medical School, Observatory, 7925, South Africa. 


\section{Results}

The results are summarised in Table I.

The pre-injection angle of esotropia averaged 38 prism dioptres (range 30-55 prism dioptres). No patient in this series had any lateral rectus function before injection, no patient could abduct beyond the midline and no patient had any contracture of the medial rectus.

Within a few days of injection, seven (cases 2 to 8 ) of the eight patients regained fusion, without the necessity of a marked head turn. The same seven patients required only one injection and eventually regained full function with normal abduction and no residual deviation. One patient (case 1) who was injected four times over a 24-month period, had no recovery of sixth never function, and required surgery. No patients were bothered by reversal of diplopia as the botulinum toxin injection took effect and all experienced a marked symptomatic improvement.

\section{Complications}

Five patients (cases 1, 3, 4, 5, 8) developed transient mild ptosis which resolved completely within eight weeks. The patient (case 1) who was injected four times, developed a small permanent vertical deviation. No systemic side effect occurred in any patient at any time during the study.

\section{Discussion}

Early injection of botulinum to the ipsilateral medial rectus allowed seven of our eight patients to enjoy and appreciate fusion in or close to the primary position, without the necessity of a marked head turn. Metz and Mazow $^{1}$ and Wagner and Frohman ${ }^{2}$ reported a marked symptomatic improvement in similar groups of patients who were injected within 12 weeks of the onset of the palsy. Elston, ${ }^{3}$ and Elston and Lee $^{4}$ initially expressed a strong argument against the use of botulinum in the acute phase of 6th nerve palsy, believing that paralysis of the medial rectus would lead to a confusing reversal of diplopia. However they have recently accepted that botulinum does in fact play a useful role in the symptomatic management of this condition. ${ }^{5}$

The prognosis for recovery of function over two or three months is excellent in most cases due to microvascular disease, and we recognise that some patients will improve or recover spontaneously without botulinum.

However, Rush and Younge ${ }^{6}$ in reviewing 419 cases of sixth nerve palsy found that irrespective of aetiology, only $49 \%$ of patients spontaneously recovered full function (Table II).

As some patients, including those with microvascular disease, will not recover spontaneously, and as this group cannot always reliably be identified in the acute stage, our results lead us to recommend early treatment of patients showing no signs of recovery two months after the onset of the palsy. Diplopia in primary gaze may be avoided, occlusion may not be necessary, and the chance of medial rectus contracture is markedly reduced. Injection at an even earlier stage may be beneficial, and we are currently evaluating patients who were injected at one month, after they had shown no improvement by then.

An unexpectedly high number of our patients $(87 \%)$ and of Metz and Mazow's ${ }^{1}$

Table I. Pre and post-injection findings

\begin{tabular}{|c|c|c|c|c|c|c|c|c|c|c|c|}
\hline \multirow[b]{2}{*}{ Case No. } & \multirow[b]{2}{*}{$\begin{array}{c}\text { Age } \\
\text { (years) }\end{array}$} & \multirow[b]{2}{*}{$\begin{array}{c}\text { No. of } \\
\text { injections }\end{array}$} & \multirow{2}{*}{$\begin{array}{c}\text { Time } \\
\text { From } \\
\text { onset of } \\
\text { palsy } \\
\text { (weeks) }\end{array}$} & \multicolumn{4}{|c|}{ Pre-injection data } & \multicolumn{4}{|c|}{ Post-injection data } \\
\hline & & & & $\begin{array}{c}\text { Deviation (prism } \\
\text { dioptres) }\end{array}$ & $\begin{array}{c}\text { Lateral } \\
\text { rectus } \\
\text { function }\end{array}$ & Abduct. & $\begin{array}{c}\text { Medial rectus } \\
\text { contracture }\end{array}$ & Final deviation & $\begin{array}{c}\text { Lateral } \\
\text { rectus } \\
\text { function }\end{array}$ & Abduct. & $\begin{array}{c}\text { Fusion } \\
\text { primary } \\
\text { position }\end{array}$ \\
\hline 1 & 64 & 4 & 5 & $40 \mathrm{ET}$ & $\mathbf{P}$ & -4 & 0 & $\begin{array}{l}35 \mathrm{ET} \\
5 \mathrm{LHT}\end{array}$ & $\mathbf{P}$ & -4 & $\mathbf{N}$ \\
\hline 2 & 34 & 1 & 5 & $55 \mathrm{ET}$ & $\mathbf{P}$ & -4 & 0 & 0 & G & 0 & $\mathrm{Y}$ \\
\hline 3 & 8 & 1 & 8 & $35 \mathrm{ET}$ & $P$ & -4 & 0 & 0 & G & 0 & $\mathrm{Y}$ \\
\hline 4 & 61 & 1 & 7 & $30 \mathrm{ET}$ & $\mathbf{P}$ & -4 & 0 & 0 & G & 0 & $\mathrm{Y}$ \\
\hline 5 & 29 & 1 & 5 & $35 \mathrm{ET}$ & $\mathbf{P}$ & -4 & 0 & 0 & G & 0 & $\mathrm{Y}$ \\
\hline 6 & 36 & 1 & 8 & $35 \mathrm{ET}$ & $\mathbf{P}$ & -4 & 0 & 0 & G & 0 & $\mathrm{Y}$ \\
\hline 7 & 49 & 1 & 5 & $35 \mathrm{ET}$ & $\mathbf{P}$ & -4 & 0 & 0 & G & 0 & $\mathrm{Y}$ \\
\hline 8 & 18 & 1 & 7 & $45 \mathrm{ET}$ & $\mathbf{P}$ & -4 & 0 & 0 & G & 0 & $\mathrm{Y}$ \\
\hline
\end{tabular}

ET = Esotropia LHT = Left Hypertroia $\mathrm{P}=$ Poor F = Fair G = Good N = No Y = Yes Abduct. = Abduction No. $=$ Number 
Table II. Causes of sixth nerve palsy and known spontaneous recovery ${ }^{6}$

\begin{tabular}{lrr}
\hline & Total & Recovery \\
\hline Undetermined & 124 & $63(50 \%)$ \\
Head trauma & 70 & $27(38 \%)$ \\
Neoplasm & 61 & $13(21 \%)$ \\
Vascular & 74 & $51(69 \%)$ \\
Aneurysm & 15 & $10(67 \%)$ \\
Other & 75 & $44(59 \%)$ \\
Total & 419 & $208(49 \%)$ \\
\hline
\end{tabular}

patients $(71 \%)$ recovered full function after injection. Because patients with sixth nerve palsy may recover spontaneously, a randomised prospective trial is needed more definitely to determine whether this form of therapy is effective in facilitating recovery of sixth nerve function.

\section{Conclusion}

Botulinum toxin plays a useful role in the early symptomatic management of lateral rec- tus palsy. Whether it facilitates the recovery of sixth nerve function has yet to be determined.

This study is supported by the South African Medical Research Council and the Leonard Townsend Gratitude Fund.

Key words: Botulinum Toxin-Early TreatmentSixth Nerve Palsy.

\section{References}

${ }^{1}$ Metz $\mathrm{H}$ and Mazow M: Botulinum toxin treatment of acute sixth and third nerve palsy. Graefe's Arch Clin Exp Ophthalmol 1988, 226: 141-4.

${ }^{2}$ Wagner RS and Frohman CP: Long-term results: Botulinum for sixth nerve palsy. J Pediatr Ophthalmol Strabismus 1989, 26: 106-8.

${ }^{3}$ Elston JS: Botulinum A toxin for ocular muscle disorders (Letter) Lancet 1986, 2: 265-6.

${ }^{4}$ Elston JS and Lee JP: Paretic strabismus: The role of botulinum toxin. $\mathrm{Br} J$ Ophthalmol 1985, 69: 891-6.

${ }^{5}$ Elston JS: Botulinum Toxin (Editorial) Aust $N Z J$ Ophthalmol 1989, 17: 209-10.

${ }^{6}$ Rush JA and Younge BR: Paralysis of cranial nerves III. IV. VI. Cause and prognosis in one thousand cases. Arch Ophthalmol 1981, 99: 76-9. 